Article

\title{
How Does Inter-Organizational Cooperation Impact Organizations' Scientific Knowledge Generation? Evidence from the Biomass Energy Field
}

\author{
Liu Li and Chaoying Tang * \\ School of Economics and Management, University of Chinese Academy of Sciences, Beijing 100190, China; \\ liuli173@mails.ucas.ac.cn \\ * Correspondence: tcy@ucas.ac.cn
}

Citation: Li, L.; Tang, C. How Does Inter-Organizational Cooperation Impact Organizations' Scientific Knowledge Generation? Evidence from the Biomass Energy Field.

Sustainability 2021, 13, 191.

https://dx.doi.org/10.3390/su13010191

Received: 26 October 2020

Accepted: 8 December 2020

Published: 28 December 2020

Publisher's Note: MDPI stays neutral with regard to jurisdictional claims in published maps and institutional affiliations.

Copyright: () 2020 by the authors. Licensee MDPI, Basel, Switzerland. This article is an open access article distributed under the terms and conditions of the Creative Commons Attribution (CC BY) license (https: / / creativecommons.org/ licenses/by/4.0/).

\begin{abstract}
Previous studies have demonstrated that accessing external knowledge is important for organizations' knowledge generation. The main purpose of this study is to investigate how the diversity and amount of organizations' external scientific knowledge influence their scientific knowledge generation. We also consider the moderating effect of the redundant industrial scientific knowledge and the amount of technical knowledge from external technical cooperators. The social network analysis method is used to establish both ego- and industrial-scientific cooperation network, and ego-technical cooperation network in order to analyze the external scientific knowledge and technical knowledge. The empirical analysis is based on patent and article data of 106 organizations in the biomass energy industry (including firms, universities and research institutes), and the results show that organizations' structural holes and degree centrality of scientific cooperation network have positive effects on their scientific knowledge generation. In addition, organizations' degree centrality of technical cooperation network positively moderates the relationship between their degree centrality of scientific cooperation network and scientific knowledge generation. Furthermore, density of industrial scientific cooperation network decreases the positive effect of organizations' structural holes on their scientific knowledge generation, while it strengthens the positive effect of degree centrality of scientific cooperation network on their scientific knowledge generation. Academic contributions and practical suggestions are discussed.
\end{abstract}

Keywords: scientific knowledge; technical knowledge; cooperation network; structural holes; degree centrality; biomass energy

\section{Introduction}

Developing clean and renewable energies has become the important strategy of handling the challenge of global climate warming [1,2]. Biomass energy supplies about $10 \%$ of the global annual energy consumption [3], and it is among the most prominent renewable energy sources $[4,5]$. Biomass energy could help to solve the problems of environmental degradation and resource depletion. The important biomass energy sources are wood and wood wastes, agricultural crops and their waste byproducts, animal wastes, waste from food processing and aquatic plants and algae [6]. These biomass materials are being converted into a suitable form of energy via different routes, such as biochemical, chemical and thermo-chemical [5-7]. The conversion routes of biomass materials can be achieved by advanced technologies [5] in order to reduce the harmful effects of fossil fuels, cut down technical cost and carry out engineering application research [8]. Modern tools of biotechnology have also emerged in order to improve the key process of biological conversion [9]. Scientific research has intensively been carried out and the significance of research on the biomass energy has been stressed [10,11]. Correspondingly, a large variety of new technologies are constantly emerging [5,9]. Advanced technical knowledge greatly promotes the process of industrial commercialization of scientific knowledge through 
providing data, research materials, etc. [12,13]. Meanwhile, the new emerged technology challenges often become the new start points of scientific research [14]. Thus, the role of technical knowledge in promoting scientific knowledge generation cannot be ignored.

Knowledge from inter-organizational cooperation has become an important source of external knowledge [15,16]. Organizations' accessed external scientific knowledge could promote the generation of organizations' scientific knowledge. Specifically, the diversity and the amount of organizations' accessed external scientific knowledge could promote the generation of their scientific knowledge. Chen et al. [17] proposed that the research institutes could integrate and absorb external scientific knowledge to enhance their scientific knowledge generation. However, we found that when industrial scientific cooperation is very close, the cooperation may not give organizations such a benefit. As the cooperators are closely connected with each other, it generates a larger amount of redundant contacts that are not conducive to acquiring unique knowledge [18]. The homogenization of knowledge will decrease the possibility of new knowledge generation [19]. Moreover, frequent communication among cooperators may lead to common understandings and similar cognition, thereby damaging the creativity of scientific research.

Previous studies also point out that science and technology interact with each other [20-24]. Science provides deep understanding and theoretical base for technology [25]. Technology is a source of new scientific challenges [14] and directed by scientific knowledge to solve real problems [26]. In this study, we focus on organizations' scientific knowledge generation, and explore the promotion of technical knowledge. For example, in the field of biomass energy, gasification of biomass is a well-known technology that converts biomass into a combustible gas by thermochemical reactions [6]. As a kind of technology, gasification of biomass is based on some of scientific research conducted in the areas of gasifier and producer gas engine [27]. Production of methanol and hydrogen by means of gasification processes is a promising way to produce electricity [28], which helps solve real electricity problems. Meanwhile, continuous development of gasification technology offers deep insight for scientific researchers through providing data, experimental gasification equipment, etc. In particular, the introduction of advanced external technologies incurs higher costs, which motivates scientific researchers to explore new ways to solve the technical problems and reduce the cost of technologies.

We use social network analysis [16,29] to study organizations' accessed external knowledge. Correspondingly, this study establishes a scientific cooperation network and technical cooperation network based on article data and patent data. In scientific cooperation network, two or more organizations are connected based on their co-authorship of an article. In a technical cooperation network, organizations are connected based on their co-assignment of a patent. To study the diversity and the amount of organizations' accessed external scientific knowledge, we analyze the structural holes and degree centrality of inter-organizational scientific cooperation network. The structural holes provide actors more chances to leverage heterogeneous knowledge [30-32], and central actors have more opportunities to acquire knowledge from cooperators without relying on mediators quickly [33]. Evidence shows that structural holes and central position both contribute to knowledge generation [34-36]. Furthermore, we establish the industrial scientific cooperation network and calculate the density of this network in order to determine the redundancy of industrial scientific knowledge. In addition, organizations' degree centrality of a technical cooperation network is used to describe the amount of their accessed external technical knowledge. Since degree centrality represents the direct relationships of organizations with their partners, increasing degree centrality provides more chances for organizations to access the external knowledge [33]. 
In this study, scientific knowledge and technical knowledge refer to scientific articles and patents, respectively, which have been widely used in previous studies [20,36-38] For example, Breschi et al. [20] combined data on scientific co-authorship with data on patent co-invention, and identified the role of key individuals in the process of knowledge transfer. Extant studies about the influence of the interactions of external scientific and technical knowledge on organizations' scientific knowledge generation remain unclear, which prevents us from comprehensively understanding scientific knowledge generation. Thus, the main purpose of this study is to investigate how the diversity and amount of organizations' external scientific knowledge influence their scientific knowledge generation. We also consider the moderating effect of the redundant industrial scientific knowledge and the amount of technical knowledge from external technical cooperators.

The theoretical contributions of this study include the following: First, previous studies have emphasized the importance of accessed external knowledge for knowledge generation $[17,24]$. This paper aims to study the influence of organizations' accessed external scientific and technical knowledge on their scientific knowledge contribution. The research question is not novel in the knowledge innovation (or generation) field [17]; nevertheless, our study explores the characteristics of organizations' external knowledge more comprehensively. That is, we not only study the diversity of organizations' external scientific knowledge (represented by the structural holes of organizations' scientific cooperation network) but also study the amount of organizations' external technical knowledge (represented by the degree centrality of organizations' technical cooperation network), and the redundancy of the industrial scientific knowledge (represented by the density of industrial scientific cooperation network). The findings of this study will enrich the extant literature about organizations' accessed external knowledge and their scientific knowledge generation. Second, most research about knowledge generation focus on the individual level [36], organizational level [17,39] or the industrial level [40]. However, there is no previous research on how the industrial scientific cooperation influences organizations' scientific knowledge generation. We respond to the appeal that the cross-level study needs more research attention [41,42], and incorporate the density of industrial scientific cooperation network into the organizations' scientific knowledge generation.

The structure of the rest of the paper is as follows: First, the literature review is provided, and six hypotheses are put forward. Second, hypotheses were examined by analyzing the data of 15,419 articles and 20,251 patents in the field of biomass energy during 2002-2017. Third, conclusions and contributions are given, and limitations and future research are discussed.

\section{Literature Review and Hypotheses}

\subsection{The Impact of Organizations' Accessed External Scientific Knowledge on Their Scientific Knowledge Generation}

Scientific knowledge generation increasingly depends on organizations' accessed external scientific knowledge. No organizations alone have all the expertise and capabilities to achieve their research goals or conduct research and development (R\&D) work by their internal knowledge [43]. Knowledge integration across organizational boundaries is important for the new knowledge generation [44]. Organizations' accessed external scientific knowledge could help their new scientific knowledge generation. In the age of open innovation, inter-organizational cooperation has become an important approach for organizations to access external knowledge [16].

The diversity of external scientific knowledge accessed from cooperators could be reflected by organizations' network position of scientific cooperation network, especially the critical role of organizations' structural holes. Structural holes are gaps in knowledge flows between members connected with the same ego but disconnected with each other [43]. The position of structural holes helps actor access different knowledge [43]. In other words, the crucial role of a "bridge" gives actors more opportunity to attain diversified external knowledge [30-32,45]. As Burt [46] pointed out, actors occupying structural holes face chances to exploit and transfer diverse knowledge. Spanning structural holes could also 
avoid the problem of homogeneity among alters [47]. There is evidence that structural holes help actors possess heterogeneous knowledge from non-redundant contacts and generate more knowledge [34-36].

Taken together, organizations bridging more structural holes of scientific cooperation network would obtain more diverse scientific knowledge, thereby generating more scientific knowledge. Based on the above discussion, the following hypothesis is proposed:

Hypothesis 1. Organizations' structural holes of scientific cooperation network positively impact their scientific knowledge generation.

On the other hand, the amount of organizations' accessed external knowledge will influence knowledge generation [16]. We use organizations' degree centrality to represent the amount of accessed external knowledge. The degree centrality of actors stands for the central position of the network $[48,49]$. The central position of the scientific cooperation network helps scientific knowledge generation. First, central actors have more opportunities to communicate with cooperators [50], and conduct more knowledge-recombination [51]. As such, central actors are more likely to gain more external knowledge. Moreover, the uncodified and tacit knowledge is more likely to be shared and transferred by close contact [30]. The sharing of tacit knowledge will contribute to knowledge generation [36]. In addition, it was found that central organizations gathered knowledge more extensively and quickly [33], which improved the possibility of accessed diversified knowledge and knowledge generation.

Based on the above discussion, the following hypothesis is proposed:

Hypothesis 2. Organizations' degree centrality of scientific cooperation network positively impacts their scientific knowledge generation.

\subsection{The Impact of the Redundant Industrial Scientific Knowledge on Organizations' Scientific Knowledge Generation}

Density of cooperation network refers to the proportion of existing links to the number of possible pairwise combinations of organizations [52]. Density of industrial scientific cooperation network indicates the average frequency of contacts among organizations in industrial scientific cooperation network. Higher network density-that is, a dense network-is characterized by the high level of connectivity among network members [53]. In a dense network, the possibility of communication among actors are increased [54,55]. However, the frequent communication will in turn bring redundant contacts that are not conducive to acquire unique knowledge [18]. As such, in a dense network, the nonredundant contacts for potential combinations are decreased and the knowledge homogenization increased $[19,55,56]$. Moreover, in a dense network, the frequent communication may lead to common understandings and similar cognition among cooperators, which also hinders organizations' scientific knowledge generation.

Therefore, in a dense network, the advantages of organizations' structural holes and degree centrality of scientific cooperation network on their scientific knowledge generation will be diminished. A similar opinion can be found in the study by Rodan and Galunic [57], which pointed out that a "network broker" residing within a relatively sparse network puts the broker in an advantageous position. As in a sparse network, more non-redundant knowledge can be accessed through structural holes. A dense network also prevents organizations from taking full benefit from their central position of the scientific cooperation network due to the fact that more redundant external scientific knowledge would be shared among central organizations. 
Taken together, we argue that density of industrial scientific cooperation network will weaken the positive effect of organizations' structural holes and degree centrality on their scientific knowledge generation. Thus, we propose the hypotheses as follows:

Hypothesis 3. Density of industrial scientific cooperation network moderates the relationship between organizations' structural holes and their scientific knowledge generation in the way that when density of industrial scientific cooperation network is high, the positive effect of structural holes on scientific knowledge generation will be weakened.

Hypothesis 4. Density of industrial scientific cooperation network moderates the relationship between organizations' degree centrality and their scientific knowledge generation in the way that when density of industrial scientific cooperation network is high, the positive effect of degree centrality on scientific knowledge generation will be weakened.

\subsection{The Impact of Organizations' Accessed External Technical Knowledge on Their Scientific Knowledge Generation}

Accessed external scientific knowledge could increase organizations' scientific knowledge generation, and the process might be influenced by their accessed external technical knowledge. As we mentioned above, technical knowledge provides data and further research material for carrying out scientific research $[12,13]$. Technologies are also directed by science to solve real problems [26]. New emerged technology challenges often become the new start points of scientific research [14].

Organizations occupying central positions of technical cooperation network can better assimilate their accessed external technical knowledge [49]. Supportive evidence includes that degree centrality increased the absorptive capacity of organizations [29]. In addition, central organizations of technical cooperation network can use more external support and obtain more inventive opportunities [34].

Similar to the above mentioned, the amount of organizations' accessed external knowledge can be analyzed by degree centrality of cooperation network. Thus, we suppose that organizations' central position of technical cooperation network could strengthen the positive effects of their structural holes and degree centrality of scientific cooperation network on scientific knowledge generation.

Therefore, we propose the following hypotheses:

Hypothesis 5. Organizations' degree centrality of technical cooperation network moderates the relationship between their structural holes of scientific cooperation network and their scientific knowledge generation in the way that when organizations' degree centrality of technical cooperation network is high, their structural holes of scientific cooperation network have a stronger positive effect on their scientific knowledge generation.

Hypothesis 6. Organizations' degree centrality of technical cooperation network moderates the relationship between their degree centrality of scientific cooperation network and their scientific knowledge generation in the way that when organizations' degree centrality of technical cooperation network is high, their degree centrality of scientific cooperation network has a stronger positive effect on their scientific knowledge generation.

Taken together, the research framework and hypotheses of this study are presented in Figure 1. 


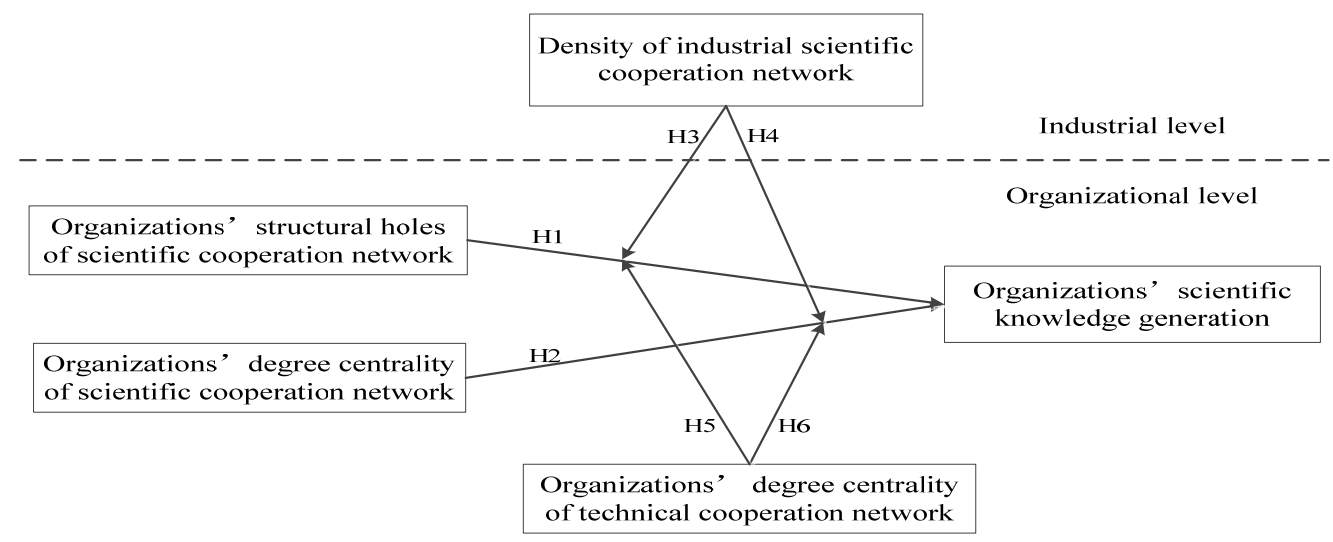

Figure 1. Research framework and hypotheses for this study.

\section{Method}

\subsection{Research Setting and Data}

We tested our hypotheses in the field of biomass energy, where publishing and patenting activities were active (Figure 2). There are two main reasons to choose data from this field. First, biomass, as an indispensable source of renewable energy, has become the fourth largest source of energy [58]. It provides about $14 \%$ of the world's energy consumption [58], and attracts the attention of R\&D managers and policy makers [59]. In 2016, biomass received fortunes regarding investment keeping steady at USD 6.8 billion [60]. Second, the significance of research on biomass energy has been stressed by a large number of high-profile papers and reviews $[10,11]$. Moreover, biomass energy yields plenty of new knowledge through inter-organizational cooperation. Thus, this field is a typical example to explore how accessed external scientific knowledge and accessed technical knowledge affect the generation of organizations' scientific knowledge.

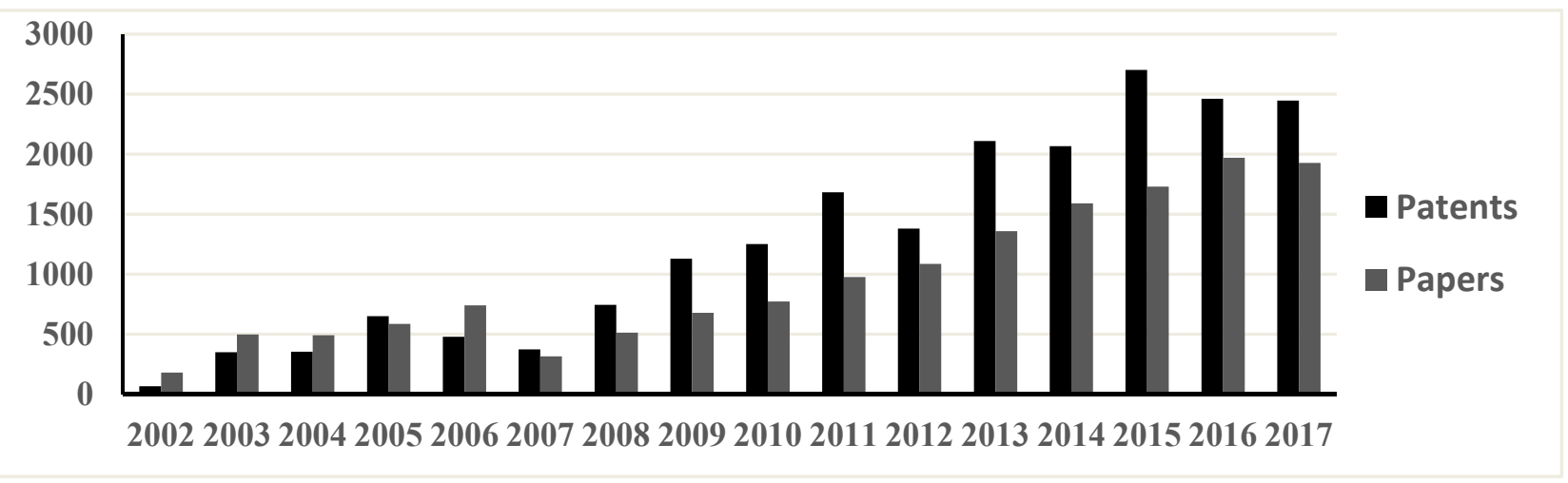

Figure 2. The number of biomass energy articles and patents-2002-2017 for this study.

Our main variables were calculated based on scientific publications and patents, which have been demonstrated the validity as proxies to measure science and technology $[61,62]$. Data collection mainly consists of two parts. One is the scientific publications. The data were acquired from the Science Citation Index Expanded (SCIE) and the Social Science Citation Index (SSCI) databases in the Web of Science of Thomson Reuters Inc. WOS is a very authoritative database, and it is popular among researchers [63]. Two sets of search terms were used as the search strategy in Table 1. We performed the retrieval and removed non-biomass literature carefully in January 2018. After a thorough cleaning the publication data, the final database contained 15,419 biomass energy articles in the period of 2002-2017, among which there are 9990 articles whose affiliations are cooperative organizations. These organizations include firms, universities or research institutes. 
Table 1. Definitions of search queries for articles and patents in the biomass energy field.

\begin{tabular}{|c|}
\hline Searching Terms \\
\hline $\begin{array}{l}\text { TI = biomass and TS = (biofuel * or "bio-fuel *" or fuel * or bioenergy or "bio-energy" or energy or } \\
\text { biomethan * or "bio-methan *" or methan * or bioethanol * or "bio-ethanol *" or ethanol * or } \\
\text { biodiesel * or "biodiesel *" or diesel * or biogas * or "bio-gas *" or gas or biooil * or "bio-oil *" or } \\
\text { oil * or biohydrogen * or hydrogen * or synfuel * or syngas * or synoil * or "syn-gas" or "syn-fuel *" } \\
\text { or "syn-oil *" or "renewable energy" or "green energy" or "biorefin" or "bio-refin *" or refinery) }\end{array}$ \\
\hline
\end{tabular}

Another is the patent data. We obtained the biomass energy patent data from Derwent Innovation Index database (DII). The database contains the most comprehensive content, covering patent information from more than 100 countries and 40 patent authorities, including USPTO, EPO, JPO and SIPO and so on. To identify the biomass energy patents from the DII database accurately, we followed the searching strategy utilized by Konur [10] and Liu et al. [59] in Table 1. The retrieving processes were performed in January 2018, and we identified 20,251 biomass energy invention patents in the period of 2002-2017. Eliminating the assignees of the patents are individual inventors, and there are 15,453 patents whose assignees are firms, universities or research institutes. Finally, 4279 patents are available because the assignees of these patents have inter-organizational cooperation. The data processing is quite tedious and time-consuming. Figure 2 shows the number of biomass energy articles and patents each year. According to the figure, the number of articles and patents have kept growing in general. Therefore, it is reasonable to carry out our research in the field of biomass energy.

Next, all the records of biomass energy articles and patents were loaded into Excel 2003. The downloaded data were cleaned up through a series of manual checking to harmonize the names of organizations. For example, the same organization may have different names, such as Peking University also called Beijing University. Some renaming phenomena and spelling mistakes happened, and we found the standard names from the official websites, Business Annual Report and World-Wide-Web. Using five-year moving window, we conducted two types of networks: scientific cooperation network and technical cooperation network. Scientific cooperation network is constructed based on organizations' co-authorship of an article, and technical cooperation network is based on the data of organizations' co-assignment of a patent. We finished the process of network construction with the help of the Science of Science $\left(\mathrm{Sci}^{2}\right)$ Tool software.

Finally, our data pool contains 106 firms, universities and research institutes as the empirical samples. The proportion of them in the samples, respectively, accounts for $15 \%, 72 \%$ and $13 \%$. The reason why we chose those organizations is that at least one article (one patent) occurred both during the previous five years ( $\mathrm{t}-1$ to $\mathrm{t}-5$ year) and in the subsequent observation year ( $t$ year) for the organization. Although there is a limited number of firms and research institutes relative to universities in our samples, they are large-scale organizations and have certain representativeness in the field. This shows that firms are also committed to publishing except for inventing patents in the biomass energy field. Publishing and patenting activities are crucial for organizations' scientific knowledge generation.

\subsection{Variables}

\subsubsection{Dependent Variable}

Organizations' scientific knowledge generation. We regarded the number of published articles as the valid proxy for organizations' scientific knowledge generation. Despite having some limitations, article-based indicators have been widely used in previous studies [36,37]. To be specific, if scientific cooperation network was conducted in 2002-2006, the dependent variable is the number of an organization's biomass energy articles in 2007. 


\subsubsection{Independent Variables}

Organizations' structural holes of scientific cooperation network. The measurement of structural holes indicates the extent of organizations' disconnected network contacts [46]. We calculated structural holes using UCINET by measuring the constraint [62]. The calculation process is as follows. We first conducted a scientific cooperation network based on organizations' co-authorship of published articles from 2002-2017. The next step was to compute structural holes values by the formula:

$$
C_{i j}=\left(P_{i j}+\sum_{q} P_{i q} P_{q j}\right)^{2}, q \neq i, q \neq j .
$$

where $P_{i j}$ equals the strength of direct ties from $i$ to $j . \sum_{q} P_{i q} P_{q j}$ is the proportion of $i$ 's indirect ties with $j$ via all $q .\left(P_{i j}+\sum_{q} P_{i q} P_{q j}\right)$ is the proportion of $i$ 's relations that are directly or indirectly invested in connection with contact $j$.

$$
C_{i}=\sum_{j} C_{i j}, i \neq j
$$

where $C_{i}$ is the network constraint index, and we calculated it based on $C_{i j}$.

$$
\mathrm{S}_{i}=1-C_{i}
$$

We adopted Zaheer and Bell's [63] method as one minus the network constraint index of the organization to measure structural holes $\mathrm{S}_{i}$.

Organizations' degree centrality of scientific cooperation network. The nodal degree is the number of adjacencies in a network (i.e., the number of nodes that the focal node is directly associated with) [64]. The computational formula is as follows [64]:

$$
D C(i)=\frac{\sum_{j} m_{i j}}{n-1}
$$

In detail, $i$ is the focal node, $j$ represents other nodes, $n$ is the total number of nodes, $m$ is the adjacency matrix. If there is a link between node $i$ and node $j, m_{i j}=1$ and 0 otherwise.

\subsubsection{Moderation Variables}

Organizations' degree centrality of technical cooperation network. Different from scientific cooperation network, this variable mainly indicates the organizations' network position of technical cooperation network. Firstly, we conducted technical cooperation network from 2002-2017. A node represents an organization (namely an assignee) and a tie means that two organizations jointly invent a patent. Secondly, we calculated degree centrality by UCINET software using the above formula, namely degree centrality of technical cooperation network.

Density of industrial scientific cooperation network. This variable describes the characteristics of industrial scientific cooperation network in the biomass energy industry. It measures the ratio of existing links to the number of possible pairwise combinations of organizations [52]. We calculated density of industrial scientific cooperation network by measuring the average frequency of contacts among organizations when they carry out scientific activities. The formula is as follows [56], where $N$ is the number of organizations in the biomass energy industry, $N_{i j}$ is the number of ties of scientific cooperation network.

$$
\text { Density }=\frac{2 * N_{i j}}{N(N-1)}
$$




\subsubsection{Control Variables}

Previous all period articles. The number of previous all period articles published before the given period $t$ can be used as the accumulation of organizations' scientific knowledge, which may affect their scientific knowledge generation in the year of observation $t$. Thus, we chose previous all period articles as the control variable for unobserved heterogeneity in article publishing.

Previous period patents. The number of previous period patents can be regarded as the accumulation of organizations' previous period technical knowledge, and it may affect their scientific knowledge generation in the year of observation $t$. Therefore, we calculated the number of patents in the previous period $t$ and took it as a control variable.

Organization type dummies. Organizational type dummies are introduced to control the propensity heterogeneity for article presentation. Universities and research institutes are better at publishing articles than firms. Thus, we chose two dummy variables, namely University dummy and Institute dummy. "University" was coded as 1 if the organization belonged to universities. "Institute" was coded as 1 if the organization belonged to research institutes. The default was the firm type.

Location dummies. We used geographical dummies to control for geographical effects. It is obvious that the global economic development is unbalanced; therefore, introducing the location dummies is necessary. Organizations were located in Europe, Asia, Oceania and North America in our samples. Hence, we included three dummy variables. The default was North America.

\subsection{Statistical Methods}

Our dependent variable, the number of articles, is a count variable and takes only non-negative integer values. It can be dealt with in a negative binomial model or Poisson regression model. Given that the dependent variable has a high extent of variance versus its mean value, we chose the negative binomial model to correct the overdispersion in our data [65]. Moreover, the Poisson regression model makes a strong assumption that the mean of data is restrained to be equivalent to its variance. The random effects models were adopted for our panel data because the fixed effects models have biased estimates when the period is short [66]. We also used a Hausman test to choose random effects or fixed effects regression models [67]. The random effects regression models are better. In order to alleviate concerns of reverse causality and avoid simultaneity, we employed the longitudinal design. The dependent variable was measured in the period of $t$ by lagged one year with independent variables in the prior period of $t-5$ to $t-1$.

\section{Results}

\subsection{Regression Results}

Descriptive statistics and correlations are provided in Table 2. In line with previous studies about organizations' scientific knowledge generation (the number of articles), organizations' structural holes of scientific cooperation network were positively related to their scientific knowledge generation $(r=0.276, p<0.01)$, and degree centrality of scientific cooperation network was also positively related to their scientific knowledge generation $(r=0.296, p<0.01)$. 
Table 2. Mean, S.D., correlations of main variables.

\begin{tabular}{|c|c|c|c|c|c|c|c|c|c|}
\hline Variable & Mean & S.D. & 1 & 2 & 3 & 4 & 5 & 6 & 7 \\
\hline 1. Organizations' scientific knowledge generation & 4.342 & 8.995 & 1 & & & & & & \\
\hline $\begin{array}{l}\text { 2. Organizations' structural holes of scientific } \\
\text { cooperation network }\end{array}$ & 0.596 & 0.378 & $0.276^{* *}$ & 1 & & & & & \\
\hline $\begin{array}{l}\text { 3. Organizations' degree centrality of scientific } \\
\text { cooperation network }\end{array}$ & 0.053 & 0.077 & $0.296 * *$ & $0.309^{* *}$ & 1 & & & & \\
\hline $\begin{array}{l}\text { 4. Density of industrial scientific } \\
\text { cooperation network }\end{array}$ & 0.004 & 0.015 & -0.007 & $-0.153^{* *}$ & 0.052 & 1 & & & \\
\hline $\begin{array}{l}\text { 5. Organizations' degree centrality of technical } \\
\text { cooperation network }\end{array}$ & 0.006 & 0.015 & -0.062 & -0.013 & 0.059 & 0.026 & 1 & & \\
\hline 6. Previous all period articles & 16.205 & 25.628 & $0.845^{* *}$ & $0.339 * *$ & $0.239 * *$ & -0.061 & -0.020 & 1 & \\
\hline 7. Previous period patents & 1.697 & 2.987 & $0.439 * *$ & -0.039 & -0.019 & 0.026 & -0.058 & $0.361 * *$ & 1 \\
\hline
\end{tabular}

Notes: ${ }^{* *} p<0.01$.

Table 3 shows the results of the random effects negative binomial regressions for organizations' scientific knowledge generation. We centralized the interaction terms to avoid collinearity when interactions entered the models [68]. Model 1 is the basic model, which includes only the control variables. Model $2-4$ adds the independent variables related to network position: organizations' structural holes and degree centrality of scientific cooperation network.

Table 3. Random-effects negative binary regression results for organizations' scientific knowledge generation.

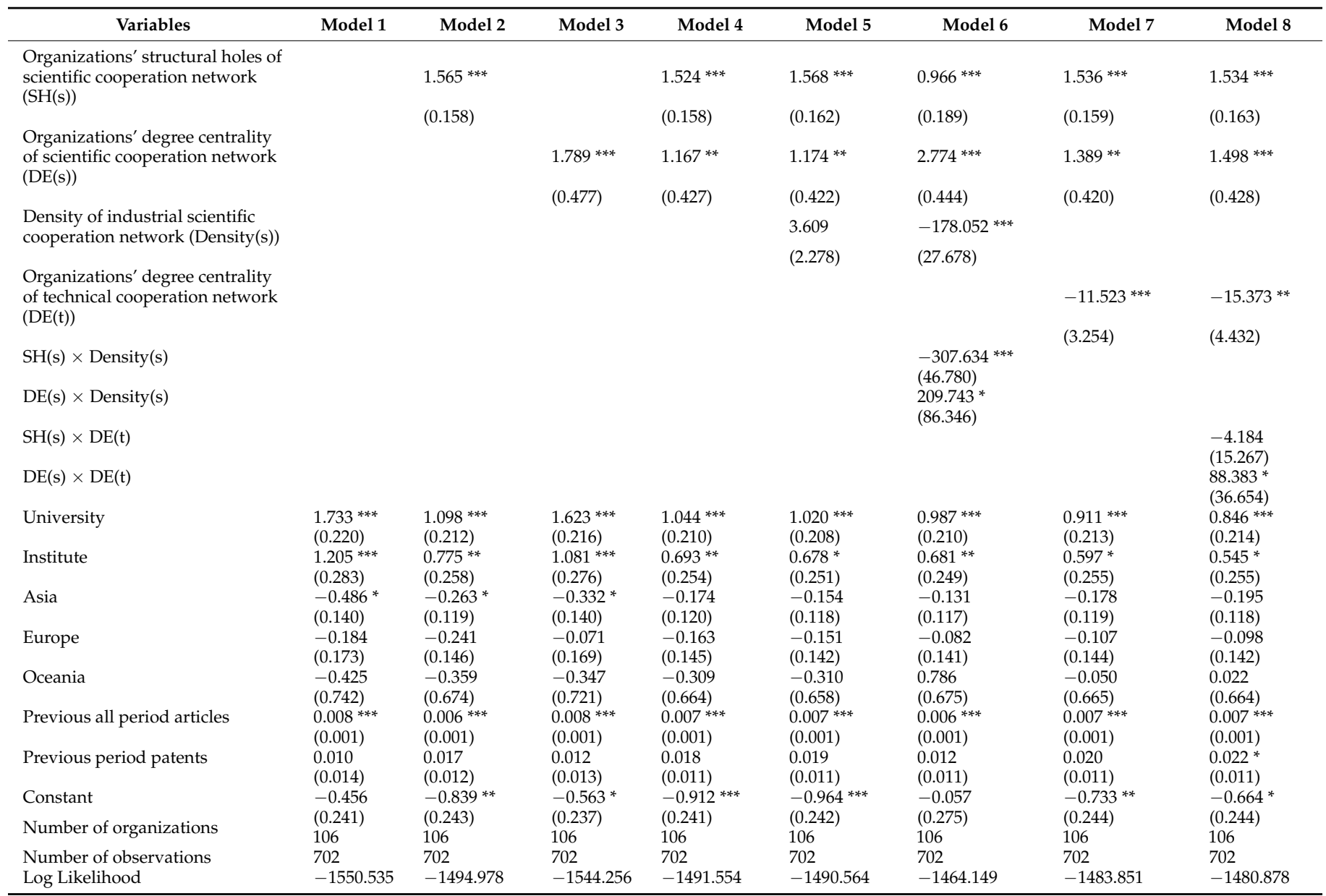


Model 5 adds the moderating variable of density of industrial scientific cooperation network. Model 6 examines the moderating effect of density of industrial scientific cooperation network by adding three variables and two interaction terms $(\mathrm{SH}(\mathrm{s}) \times$ Density $(\mathrm{s})$, $\mathrm{DE}(\mathrm{s}) \times$ Density(s)). To test the moderating effect of network position of technical cooperation network, degree centrality is entered in Model 7, and the interaction terms $(\mathrm{SH}(\mathrm{s}) \times \mathrm{DE}(\mathrm{t}), \mathrm{DE}(\mathrm{s}) \times \mathrm{DE}(\mathrm{t}))$ are entered in Model 8 .

Hypothesis 1 posits that organizations' structural holes of scientific cooperation network would positively impact their scientific knowledge generation. As expected, the results revealed that organizations' structural holes of scientific cooperation network positively affect their scientific knowledge generation (see model $4, \beta=1.524, p<0.001$ ), which show that organizations' structural holes of scientific cooperation network had a significant and positive effect on their scientific knowledge generation. Thus, Hypothesis 1 is supported.

Hypothesis 2 predicts that organizations' degree centrality of scientific cooperation network would positively affect their scientific knowledge generation. In Table 3, we found a positive effect of organizations' degree centrality of scientific cooperation network on their scientific knowledge generation (see model $4, \beta=1.167, p<0.01$ ), which is in support of Hypothesis 2. Hypotheses 3 and 4 propose the negative effects of density of industrial scientific cooperation network on the relationship between organizations' structural holes or degree centrality and scientific knowledge generation. We found that, at the industry level, density of industrial scientific cooperation network negatively moderates the relationship between organizations' structural holes and their scientific knowledge generation, while it positively moderates the relationship between organizations' degree centrality of scientific cooperation network and their scientific knowledge generation (see model 6 , $\beta=-307.634, p<0.001 ; \beta=209.743, p<0.05$, respectively). The interaction effect is shown in Figures 3 and 4 . As shown, when density of industrial scientific cooperation network is at a high level, the positive effect of organizations' structural holes of scientific cooperation network on their scientific knowledge generation is weakened, while the positive effect of degree centrality of scientific cooperation network on their scientific knowledge generation is strengthened. Thus, Hypothesis 3 is verified; however, Hypothesis 4 is not verified.

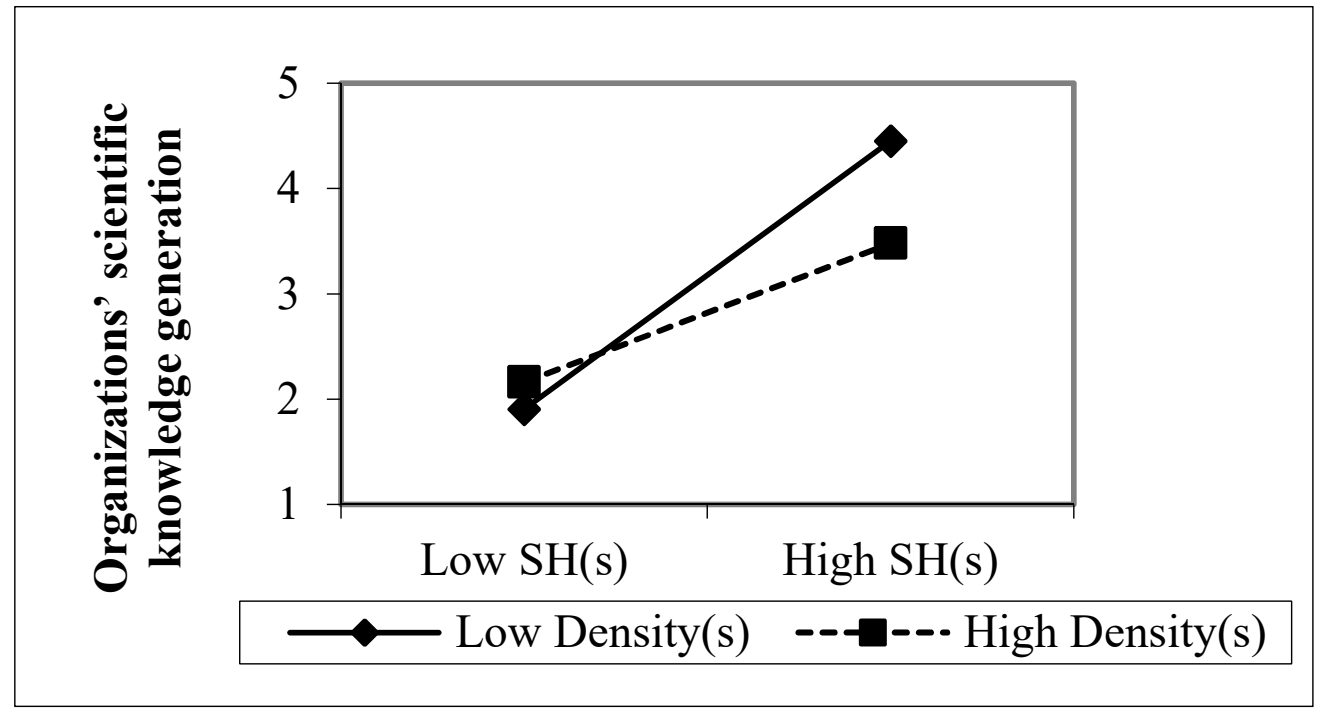

Figure 3. The moderating effect of density of industrial scientific cooperation network for this study. 


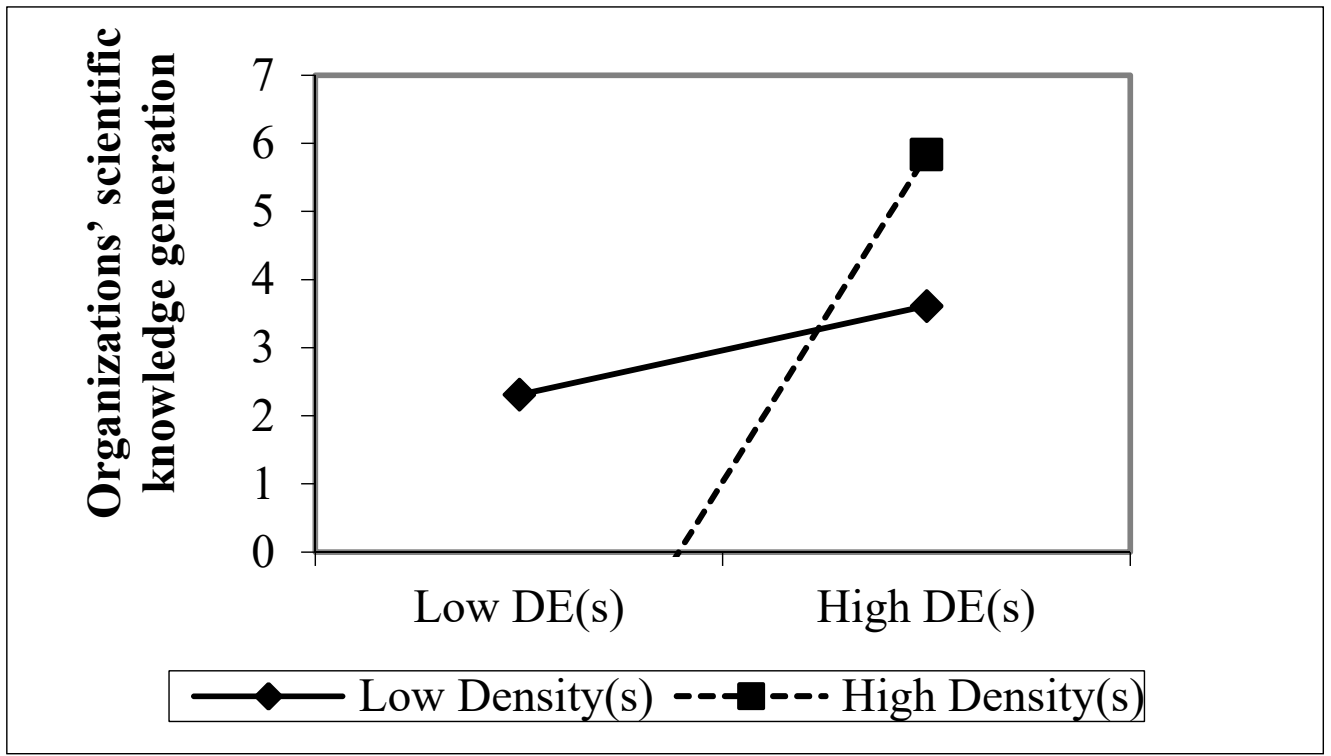

Figure 4. The moderating effect of density of industrial scientific cooperation network for this study.

Hypotheses 5 and 6 state that degree centrality of technical cooperation network positively moderates the relationship between organizations' structural holes or degree centrality of scientific cooperation network and their scientific knowledge generation. As shown in Table 3, we obtained a significant coefficient of $\mathrm{DE}(\mathrm{s}) \times \mathrm{DE}(\mathrm{t})$ (see model 8, $\beta=88.383, p<0.05$ ). To clearly illustrate the interaction effect between organizations' degree centrality of scientific cooperation network and their degree centrality of technical cooperation network, the result is plotted in Figure 5. We can see that when organizations' degree centrality of technical cooperation network is high, the positive effect of their degree centrality of scientific cooperation network on scientific knowledge generation is enhanced (the positive slope is larger), thereby supporting Hypothesis 6 . Nonetheless, the significant coefficient of interaction terms of $\mathrm{SH}(\mathrm{s}) \times \mathrm{DE}(\mathrm{t})$ is not significant (see model $5, \beta=-4.184$, $p>0.05)$. Thus, Hypothesis 5 is not corroborated.

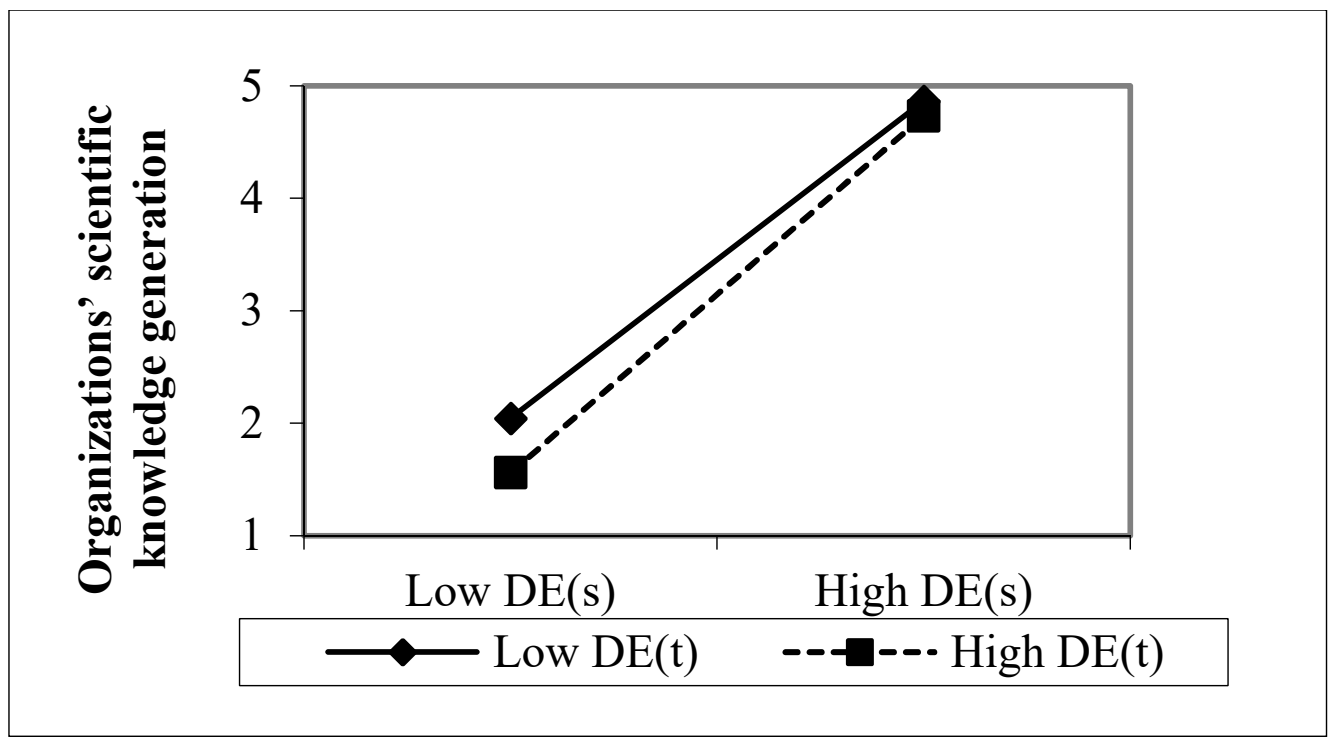

Figure 5. The moderating effect of organizations' degree centrality of technical cooperation network for this study. 


\subsection{Robust Tests}

We provide additional analysis to confirm the robustness of the results. Firstly, we chose the Tobit regression model by putting the logarithm of the article number plus 1 as the dependent variable. The results show that the main effect is confirmed $(\beta=1.006$, $p<0.001 ; \beta=1.682, p<0.001$, respectively). The moderating effect of density of industrial scientific cooperation network is also corroborated $(\beta=-170.035, p<0.001 ; \beta=207.739$, $p<0.05$, respectively). Moreover, organizations' degree centrality of technical cooperation network positively moderates the relationship between degree centrality of scientific cooperation network and their scientific knowledge generation $(\beta=72.209, p<0.05)$. All the results of Tobit regression are consistent with previous findings. Secondly, we used the hierarchy to measure structural holes of scientific cooperation network to further verify our research findings. The results show that organizations' structural holes and degree centrality of scientific cooperation network positively affect their scientific knowledge generation ( $\beta=1.986, p<0.001 ; \beta=1.502, p<0.01$, respectively). As for the moderating effects of density of industrial scientific cooperation network, we observed negative and positive (although not significant) coefficients $(\beta=-61.689, p>0.05 ; \beta=31.958, p>0.05$, respectively). Furthermore, organizations' degree centrality of technical cooperation network positively moderates the relationship between degree centrality of scientific cooperation network and their scientific knowledge generation $(\beta=95.279, p<0.05)$. The results are mainly consistent with our original findings, although supports for the Hypothesis 3 and 4 are not statistically significant. Overall, our analysis indicates that the previously reported findings are robust.

\section{Discussions and Conclusions}

\subsection{Main Findings}

Our study focuses on the influence of external scientific and technical knowledge on organizations' scientific knowledge generation in the field of biomass energy. Specifically, the influences of the diversity and the amount of organizations' external scientific knowledge on their scientific knowledge generation were explored. Furthermore, the redundancy of industrial scientific knowledge and the amount of organizations' external technical knowledge as moderators were included in the model. The main findings are as follows. Firstly, our results revealed that organizations' structural holes and degree centrality of scientific cooperation network positively influence their scientific knowledge generation. The rich structural holes help bring variety of external heterogeneous knowledge [30-32,34-36,45]. Organizations with central position can access more external knowledge, and thus have more opportunities of knowledge-recombination [51] and accessing varied knowledge [33]. Secondly, we found that density of industrial scientific cooperation network decreases the benefit that organizations take from their structural holes of scientific cooperation network on their scientific knowledge generation. The main reason for this is that redundant contacts in dense network will decrease the diversified knowledge from cooperators $[18,55]$. Thirdly, we also revealed that organizations' degree centrality of technical cooperation network promotes the benefit of degree centrality of organizations' scientific cooperation network on their scientific knowledge generation. Our explanations include that organizations occupying central positions of technical cooperation network can better assimilate their accessed external technical knowledge [49].

Nevertheless, we found that density of industrial scientific cooperation network increases the benefit that organizations take from their degree centrality of scientific cooperation network on their scientific knowledge generation. The main reason for this may be that central firms with more direct ties would have lower knowledge searching costs and better searching efficiency. Centrality is also largely associated with the organizations ${ }^{\prime}$ network status, which could attract more valuable resources in the industry and thus benefit their scientific knowledge generation. 
Moreover, we failed to find that organizations' degree centrality of technical cooperation network moderates the relationship between structural holes of scientific cooperation network and their scientific knowledge generation. Our understanding is that as abovementioned, technologies provide data and further research material for carrying out scientific research $[12,13]$. More external technical knowledge is beneficial to the positive effect of more external scientific knowledge of scientific cooperation network on organizations' scientific knowledge generation. Thus, it will strengthen the benefit of central position of scientific knowledge network on scientific knowledge generation. However, technical knowledge is more practice oriented, and it would relate to the limited specific scientific knowledge. In particular, the sample field of this study is biomass energy, which contains various scientific research areas. The potential of biomass energy and different conversion routes make scientific research of biomass energy more diverse. It is hard for organizations to find deep insight from external technical knowledge to meet the diversified needs of scientific research. Thus, it might be that the most diversified scientific knowledge which organizations gain through structural holes will be out of the scope of their technical activities. As such, the data and research materials provided by external technical activities cannot contribute to the research work of science. Organizations cannot gain insight into new scientific research questions from their external technical knowledge. Therefore, there is no moderating effect. This finding suggests to us that technical knowledge can improve scientific knowledge generation, but it is not unlimited.

\subsection{Theoretical Contributions and Practical Implications}

The main theoretical contributions of this study include the following: First, it contributes to more comprehensive understanding of the impact of the characteristics of organizations' accessed external scientific knowledge on their scientific knowledge generation. Previous studies have emphasized the importance of accessed external knowledge for knowledge generation $[17,24]$, and this paper aimed to study the influence of organizations' accessed external scientific and technical knowledge on their scientific knowledge contribution. The research question is not novel in the knowledge innovation (or generation) field. For example, Chen et al. [17], based on the Chinese Academy of Sciences' interorganizational research collaboration networks with industries and universities, and they found that the research institutes' scientific knowledge generation is significantly affected by their network positions in the research collaboration networks with industries and universities. However, our study explores the characteristics of organizations' external knowledge more comprehensively. That is, we not only studied the diversity of organizations' external scientific knowledge (represented by the structural holes of organizations' scientific cooperation network) but also the amount of organizations' external technical knowledge (represented by the degree centrality of organizations' technical cooperation network), and the redundancy of the industrial scientific knowledge (represented by the density of industrial scientific cooperation network). As such, our analysis of organizations' accessed external knowledge and their scientific knowledge generation is more comprehensive.

Second, this study contributes to the understanding of the cross-level moderating effect of density of industrial scientific cooperation network in driving organizations' scientific knowledge generation. To date, extant studies have addressed knowledge generation at the individual level [36,69], organizational level [17,39] or industrial level [40]. For example, Guan and Pang [36] analyzed the data of 3100 papers published in the Scientometrics in 1996-2015 and found that the structural holes of authors in the collaboration networks have positive effects on their scientific knowledge generation. Similarly, Wang [69] used a panel of 1042 American scientists in five disciplines and found an inverted U-shaped relationship between network average tie strength and scientific knowledge generation. Surprisingly, however, it has remained relatively unknown how the industrial scientific knowledge plays a moderating role in generating organizations' scientific knowledge. This study demonstrated the cross-level effect on scientific knowledge generation, which helps us to systematically understand the issue. 
Based on the findings of this study, we suggest practical implications as follows: First, organizations should engage in inter-organizational R\&D cooperation to access more external scientific and technic knowledge. To date, there is still more room for organizations to establish cooperation in the field of biomass energy [8]. For universities and research institutes, scientific research cooperation will improve their scientific knowledge generation. It is also necessary for them to be more active towards technical projects, or keep learning from firms, update their knowledge about the real world, and learn news about the development of technology, which will help them keep up with external technical knowledge. For firms, conducting more industry-university-research cooperation and establishing technical cooperation through joint-projects will help them gain more technical knowledge and facilitate their output of scientific research. Second, if the organizations join in various scientific areas through cooperation, maintaining the central position of technical cooperation network might not be a wise strategy. It would be hard for them to use the accessed external technical knowledge to improve their understanding of diversified scientific knowledge, which is not conducive to scientific discovery. However, when organizations have intensive cooperation in scientific research cooperation, they can choose to occupy the central position of the technical cooperation network in order to take more value from their external scientific knowledge.

Third, in the dense scientific cooperation industry, being in central and bridge positions will still help organizations improve their scientific knowledge generation, but with a weakened effect. As such, organizations might trade-off the effort of maintaining central position and bridge position.

\subsection{Limitations and Future Research}

These findings should be viewed in light of the limitations of this study, which also provide opportunities for future research. First, we measured organizations' scientific knowledge generation by counting the number of scientific publications. Nevertheless, more effective methods are needed as a proxy for scientific knowledge generation. The citation is regarded as an objective measure of the impact of published articles, and our future research could combine the two approaches to generate more precise measurements for organizations' scientific knowledge generation. Second, the sample of our study was only from the field of biomass energy; whether the conclusions can be applied to other industries is not known. In order to obtain a generalized conclusion, several other industries should be applied in the future, such as biopharmaceutical industries. Third, our study focuses on the influence of external scientific knowledge and external technical knowledge on organizations' scientific knowledge generation. Furthermore, we can explore the joint effect of organizations' internal and external knowledge access on their knowledge generation in the future.

Author Contributions: Conceptualization, L.L. \& C.T.; Data curation, L.L.; Formal analysis, L.L.; Funding acquisition, C.T.; Methodology, L.L.; Project administration, C.T.; Resources, C.T.; Supervision, C.T.; Writing-Original draft, L.L.; Writing—Review \& editing, L.L. \& C.T. Both authors have read and agreed to the published version of the manuscript.

Funding: This research was funded by National Natural Science Foundation of China, grant number 71673264, 71974178. The APC was funded by 71673264, 71974178.

Conflicts of Interest: The authors declare no conflict of interest. 


\section{References}

1. Panwar, N.L.; Kaushik, S.C.; Kothari, S. Role of renewable energy sources in environmental protection: A review. Renew. Sust. Energy Rev. 2011, 15, 1513-1524. [CrossRef]

2. Li, M.; Luo, N.; Lu, Y. Biomass energy technological paradigm (BETP): Trends in this sector. Sustainability 2017, 9, 567. [CrossRef]

3. Manzano-Agugliaro, F.; Alcayde, A.; Montoya, F.G.; Zapata-Sierra, A.; Gil, C. Scientific production of renewable energies worldwide: An overview. Renew. Sust. Energy Rev. 2013, 18, 134-143. [CrossRef]

4. Bhattacharya, S.C.; Salam, P.A.; Pham, H.L.; Ravindranath, N.H. Sustainable biomass production for energy in selected asian countries. Biomass Bioenergy 2003, 25, 471-482. [CrossRef]

5. Chintala, V. Production, upgradation and utilization of solar assisted pyrolysis fuels from biomass-A technical review. Renew. Sustain. Energy Rev. 2018, 90, 120-130. [CrossRef]

6. Demirbas, M.F.; Balat, M.; Balat, H. Potential contribution of biomass to the sustainable energy development. Energy Conv. Manag. 2009, 50, 1746-1760. [CrossRef]

7. Tareen, W.U.K.; Dilbar, M.T.; Farhan, M.; Ali Nawaz, M.; Durrani, A.W.; Memon, K.A.; Mekhilef, S.; Aamir, M.; Horan, B.; Amir, M.; et al. Present status and potential of biomass energy in Pakistan based on existing and future renewable resources. Sustainability 2020, 12, 249. [CrossRef]

8. Mao, G.; Huang, N.; Chen, L.; Wang, H. Research on biomass energy and environment from the past to the future: A bibliometric analysis. Sci. Total Environ. 2018, 635, 1081-1090. [CrossRef] [PubMed]

9. Wyman, C.E.; Dale, B.E.; Elander, R.T.; Holtzapple, M.; Ladisch, M.R.; Lee, Y.Y. Coordinated development of leading biomass pretreatment technologies. Bioresour. Technol. 2005, 96, 1959. [CrossRef] [PubMed]

10. Konur, O. The scientometric evaluation of the research on the production of bioenergy from biomass. Biomass Bioenergy 2012, 47, 504-515. [CrossRef]

11. Mao, G.Z.; Zou, H.Y.; Chen, G.Y.; Du, H.B.; Jian, Z. Past, current and future of biomass energy research: A bibliometric analysis. Renew. Sustain. Energy Rev. 2015, 52, 1823-1833. [CrossRef]

12. Perkmann, M.; Walsh, K. Engaging the scholar: Three types of academic consulting and their impact on universities and industry. Res. Policy 2008, 37, 1884-1891. [CrossRef]

13. Gersbach, H.; Sorger, G.; Amon, C. Hierarchical growth: Basic and applied research. J. Econ. Dyn. Control 2018, 90, 434-459. [CrossRef]

14. Brooks, H. The relationship between science and technology. Res. Policy 1994, 23, 477-486. [CrossRef]

15. Lace, N. The open innovation model of coaching interaction in organizations for sustainable performance within the life cycle. Sustainability 2018, 10, 3516.

16. Muller, P.; Penin, J. Why do firms disclose knowledge and how does it matter? J. Evol. Econ. 2006, 16, 85-108. [CrossRef]

17. Chen, K.; Zhang, Y.; Zhu, G.; Mu, R. Do research institutes benefit from their network positions in research collaboration networks with industries or/and universities? Technovation 2020, 94, 102002. [CrossRef]

18. Hemphälä, J.; Magnusson, M. Networks for innovation-But what networks and what innovation? Creat. Innov. Manag. 2012, 21, 3-16. [CrossRef]

19. Duysters, G.; Lemmens, C. Alliance group formation: Enabling and constraining effects of embeddedness and social capital in strategic technology alliance networks. Int. Stud. Manag. Organ. 2003, 33, 49-68. [CrossRef]

20. Breschi, S.; Catalini, C. Tracing the links between science and technology: An exploratory analysis of scientists' and inventors' networks. Res. Policy 2010, 39, 14-26. [CrossRef]

21. Chang, S.H. A pilot study on the connection between scientific fields and patent classification systems. Scientometrics 2018, 114, 951-970. [CrossRef]

22. Hullmann, A.; Meyer, M. Publications and patents in nanotechnology. Scientometrics 2003, 58, 507-527. [CrossRef]

23. Zhao, Q.; Guan, J. Love dynamics between science and technology: Some evidences in nanoscience and nanotechnology. Scientometrics 2013, 94, 113-132. [CrossRef]

24. Choi, H.; Shin, J.; Hwang, W.S. Two faces of scientific knowledge in the external technology search process. Technol. Forecast. Soc. Chang. 2018, 133, 41-50. [CrossRef]

25. Tussen, R.J.W.; Buter, R.K.; Leeuwen, T.N.V. Technological relevance of science: An assessment of citation linkages between patents and research papers. Scientometrics 2000, 47, 389-412. [CrossRef]

26. Audretsch, D.B.; Bozeman, B.; Combs, K.L.; Feldman, M.; Link, A.N.; Siegel, D.S.; Stephan, P.; Tassey, G.; Wessner, C. The economics of science and technology. J. Technol. Transf. 2002, 27, 155-203. [CrossRef]

27. Dasappa, S.; Paul, P.J.; Mukunda, H.S.; Rajan, N.K.S.; Sridhar, G.; Sridhar, H.V. Biomass gasification technology-A route to meet energy needs. Curr. Sci. 2004, 87, 908-916.

28. McKendry, P. Energy production from biomass (part 1): Overview of biomass. Bioresour. Technol. 2002, 83, 37-46. [CrossRef]

29. Zaheer, A.; Gözübüyük, R.; Milanov, H. It's the connections: The network perspective in interorganizational research. Acad. Manag. Perspect. 2010, 24, 62-77.

30. Baum, J.A.; Ingram, P. Interorganizational Learning and Network Organization: Toward a Behavioral Theory of the Interfirm. In The Economics of Choice, Change, and Organization: Essays in Memory of Richard M. Cyert; Augier, M., March, J.G., Eds.; Edward Elgar: Cheltenham, UK, 2002; pp. 191-218. 
31. Rodan, S. Structural holes and managerial performance: Identifying the underlying mechanisms. Soc. Netw. 2010, 32, 168-179. [CrossRef]

32. Liao, Y.C.; Phan, P.H. Internal capabilities, external structural holes network positions, and knowledge creation. J. Technol. Transf. 2016, 41, 1148-1167. [CrossRef]

33. Yang, H.; Lin, Z.; Peng, M.W. Behind acquisitions of alliance partners: Exploratory learning and network embeddedness. Acad. Manag. J. 2011, 54, 1069-1080. [CrossRef]

34. Wang, C.; Rodan, S.; Fruin, M.; Xu, X. Knowledge networks, cooperation networks, and exploratory innovation. Acad. Manag. J. 2014, 57, 459-514. [CrossRef]

35. Guan, J.; Yan, Y.; Zhang, J.J. The impact of collaboration and knowledge networks on citations. J. Informetr. 2017, 11, 407-422 [CrossRef]

36. Guan, J.; Pang, L. Bidirectional relationship between network position and knowledge creation in Scientometrics. Scientometrics 2018, 115, 201-222. [CrossRef]

37. Huang, M.H.; Yang, H.W.; Chen, D.Z. Increasing science and technology linkage in fuel cells: A cross citation analysis of papers and patents. J. Informetr. 2015, 9, 237-249. [CrossRef]

38. Popp, D. From science to technology: The value of knowledge from different energy research institutions. Res. Policy 2017, 46, 1580-1594. [CrossRef]

39. Popadiuk, S.; Choo, C.W. Innovation and knowledge creation: How are these concepts related? Int. J. Inf. Manag. 2006, 26, 302-312 [CrossRef]

40. Lin, C.; Yen, D.C.; Tarn, D.D. An industry-level knowledge management model-A study of information-related industry in Taiwan. Inf. Manag. 2007, 44, 22-39. [CrossRef]

41. Schwab, A. Incremental organizational learning from multilevel information sources: Evidence for cross-level interactions. Organ. Sci. 2007, 18, 233-251. [CrossRef]

42. Gupta, A.K.; Tesluk, P.E.; Taylor, M.S. Innovation at and across multiple levels of analysis. Organ. Sci. 2007, 18, 885-897. [CrossRef]

43. Ahuja, G. Cooperation networks, structural holes, and innovation: A longitudinal study. Adm. Sci. Q. 2000, 45, 425-455. [CrossRef]

44. Powell, W.W.; Koput, K.W.; Smith-Doerr, L. Interorganizational collaboration and the locus of innovation: Networks of learning in biotechnology. Adm. Sci. Q. 1996, 41, 116-145. [CrossRef]

45. Tang, C.; Zhang, G.; Naumann, S.E. When do structural holes in employees' networks improve their radical creativity? A moderated mediation model. $R$ D Manag. 2017, 47, 755-766. [CrossRef]

46. Burt, R.S. Structural Holes: The Social Structure of Competition; Harvard University Press: Cambridge, MA, USA, 1992.

47. Zaheer, A.; Soda, G. Network evolution: The origins of structural holes. Adm. Sci. Q. 2009, 54, 1-31. [CrossRef]

48. Bonacich, P. Power and centrality: A family of measures. Am. J. Sociol. 1987, 92, 1170-1182. [CrossRef]

49. Borgatti, S.P.; Carley, K.M.; Krackhardt, D. On the robustness of centrality measures under conditions of imperfect data. Soc. Netw. 2006, 28, 124-136. [CrossRef]

50. Ahuja, M.K.; Galletta, D.F.; Carley, K.M. Individual centrality and performance in virtual R\&D groups: An empirical study. Manag. Sci. 2003, 49, 21-38.

51. Rotolo, D.; Messeni Petruzzelli, A. When does centrality matter? Scientific productivity and the moderating role of research specialization and cross-community ties. J. Organ. Behav. 2013, 34, 648-670. [CrossRef]

52. Schilling, M.A.; Phelps, C.C. Interfirm cooperation networks: The impact of large-scale network structure on firm innovation. Manag. Sci. 2007, 53, 1113-1126. [CrossRef]

53. Rodrigo-Alarcón, J.; García-Villaverde, P.M.; Parra-Requena, G.; Ruiz-Ortega, M.J. Innovativeness in the context of technological and market dynamism: The conflicting effects of network density. J. Organ. Chang. Manag. 2017, 30, 548-568. [CrossRef]

54. Reagans, R.; Zuckerman, E.W. Networks, diversity, and productivity: The social capital of corporate R\&D teams. Organ. Sci. 2001, 12, 502-517.

55. Bodin, Ö.; Crona, B.I. The role of social networks in natural resource governance: What relational patterns make a difference? Glob. Environ. Chang. 2009, 19, 366-374. [CrossRef]

56. Tan, J.; Zhang, H.; Wang, L. Network closure or structural hole? The conditioning effects of network-level social capital on innovation performance. Entrep. Theory Pract. 2015, 39, 1189-1212. [CrossRef]

57. Rodan, S.; Galunic, C. More than network structure: How knowledge heterogeneity influences managerial performance and innovativeness. Strateg. Manag. J. 2004, 25, 541-562. [CrossRef]

58. Saxena, R.C.; Adhikari, D.K.; Goyal, H.B. Biomass-based energy fuel through biochemical routes: A review. Renew. Sustain. Energy Rev. 2009, 13, 167-178. [CrossRef]

59. Liu, W.; Gu, M.; Hu, G.; Li, C.; Liao, H.; Tang, L.; Shapira, P. Profile of developments in biomass-based bioenergy research: A 20-year perspective. Scientometrics 2014, 99, 507-521. [CrossRef]

60. Bloomberg. Global Trends in Renewable Energy Investment 2017. Available online: http://fs-unep-centre.org/publications/ global-trends-renewable-energy-investment-2017 (accessed on 10 January 2018).

61. Porter, A.L.; Youtie, J.; Shapira, P.; Schoeneck, D.J. Refining search terms for nanotechnology. J. Nanoparticle Res. 2008, 10, 715-728. [CrossRef] 
62. Borgatti, S.P.; Everett, M.G.; Freeman, L.C. UCINET 6 for Windows: Software for Social Network Analysis; Analytic Technologies: Harvard, MA, USA, 2002.

63. Zaheer, A.; Bell, G.G. Benefiting from network position: Firm capabilities, structural holes, and performance. Strateg. Manag. J. 2005, 26, 809-825. [CrossRef]

64. Freeman, L.C. Centrality in social networks conceptual clarification. Soc. Netw. 1978, 1, 215-239. [CrossRef]

65. Hausman, J.A.; Hall, B.H.; Griliches, Z. Econometric models for count data with an application to the patents-R\&D relationship. Econometrica 1984, 52, 909-938.

66. Greene, W.H. Econometric Analysis, 3rd ed.; Macmillan: New York, NY, USA, 1997.

67. Hausman, J.A. Specification tests in econometrics. Econometrica 1978, 46, 1251-1271. [CrossRef]

68. Aiken, L.S.; West, S.G. Multiple Regression: Testing and Interpreting Interactions; Sage: Thousand Oaks, CA, USA, 1991.

69. Wang, J. Knowledge creation in collaboration networks: Effects of tie configuration. Res. Policy 2016, 45, 68-80. [CrossRef] 